\title{
The risk of lymph node metastasis in gastric cancer conforming to indications of endoscopic resection and pylorus-preserving gastrectomy: a single-center retrospective study
}

Wu Yanzhang ${ }^{\dagger}$, Li Guanghua ${ }^{\dagger}$, Zhou Zhihao, Wang Zhixiong ${ }^{*}$ and Wang Zhao*

\begin{abstract}
Background: Lymph node metastasis (LNM) status is an important prognostic factor that strongly influences the treatment decision of early gastric cancer (EGC). This study aimed to evaluate the pattern and clinical significance of LNM in EGC.

Methods: A total of 354 patients with carcinoma in situ $(n=42)$, EGC $(n=312)$ who underwent radical gastrectomy were enrolled. Their clinicopathological features, pathological reports, and prognostic data were collected and analyzed.

Results: The incidence of LNM in all patients was $18.36 \%$ (65/354). The rates of D1 and D2 station metastases were $12.10 \%(43 / 354)$ and $6.21 \%(22 / 354)$, respectively. The rates of LNM in absolute indication of endoscopic resection and expanded indication were 3.27\% (2/61) and 28.55\% (4/14), respectively. Skip LNM was observed in 3.67\% (13/354) of patients. For those with middle-third tumor, the metastasis rate of the No. 5 lymph node was 3.05\% (5/164). The independent risk factors for LNM were tumors measuring $>30 \mathrm{~mm}$, poorly differentiated tumors, and lymphovascular invasion (all $P<0.05$; area under the curve, 0.783). The 5-year disease-free survival rates of patients with and without LNM were 96.26 and $79.17 \%$, respectively $(P=0.011)$. Tumors measuring $>20 \mathrm{~mm}$ and LNM were independent predictive factors for poor survival outcome in all patients.

Conclusions: Patients with EGC conforming to expanded indications have a relatively high risk of LNM and may not be suitable for endoscopic submucosal dissection. Pylorus-preserving gastrectomy for patients with middle-third EGC remains controversial due to the high metastasis rate of the No. 5 lymph node.
\end{abstract}

Keywords: Lymph node metastasis, Lymphatic invasion, Skip metastasis, Early gastric cancer, Predictive model

*Correspondence: wangzhx5@mail2.sysu.edu.cn; wangzhao@mail.sysu.edu.cn 'Wu Yanzhang and Li Guanghua contributed equally to this work. Department of Gastrointestinal Surgery, First Affiliated Hospital of Sun Yat-sen University, Zhongshan 2nd street, No. 58, Guangzhou 510080, Guangdong, China

\section{Background}

Gastric cancer (GC) is the fifth most common cancer type and the third leading cause of cancer-related mortality worldwide [1]. About $75 \%$ of cases appear in Asia, particularly in China, Korea, and Japan. China accounted for $50 \%$ of the new cases [2]. Over the past several decades, these Eastern Asian countries have made great efforts to prolong the survival time and improve the quality of life of patients with GC. One of the great achievements is the 
improvement of screening strategies for early GC (EGC) detection. It has been reported that the detection rate of EGC increased to $61 \%$ in Korea [3].

EGC has been defined as invasive gastric cancer confined to the mucosa or submucosa layer of the stomach, regardless of lymph node metastasis (LNM) [4]. Compared to advanced GC, EGC has a high 5-year survival rate, up to $99 \%$. D2 lymphadenectomy with gastrectomy has been the standard surgical procedure for advanced GC. The treatment decision for EGC seems to be complicated, diversified, and controversial compared with that of advanced GC. According to the 2018 Japanese GC treatment guidelines [5], endoscopic resection (ER) has been recommended as an alternative curative treatment for patients with EGC with indications. In addition to ER treatment, some modified surgical procedures, such as pylorus-preserving gastrectomy (PPG), and segmental gastrectomy, can be considered for EGC with a low risk of LNM and are not suitable for ER to improve the quality of life.

LNM status is an important prognostic factor of EGC [6-8]. According to the 2018 Japanese GC treatment guidelines [5], the choice of ER for EGC treatment is mainly dependent on the risk of LNM. LNM in patients with EGC within absolute indications for endoscopic mucosal resection (EMR) or endoscopic submucosal dissection (ESD) has been hypothesized to be negligible $(<1 \%)$. Currently, ESD is widely used as a standard method for EGC in Japan, and its indications are expanded. However, several problems remain. First, although most evidence suggests that the risk of LNM in patients with absolute indications is negligible, the results between these studies were inconsistent [5]. Second, the expanded indications for ESD remain controversial. Third, the management of cases with noncurative resection after ER is controversial.

Furthermore, there have been relatively few studies on the positive rate of each lymph node station and skip metastasis in EGC [9-13]. The definition of skip metastasis in GC cases refers to the presence of extraperigastric LNM without perigastric lymph node involvement [10]. In the present study, we aimed to elucidate the precise distribution of LNM by analyzing the metastasis status of each lymph node station in patients with EGC who underwent D2 lymphadenectomy with gastrectomy and to explore the clinical significance of LNM pattern and skip metastasis in making treatment decisions for EGC.

\section{Methods}

\section{Patient cohort and data collection}

The clinicopathological data of patients $(n=2245)$ who underwent D2 lymphadenectomy gastrectomy at the First Affiliated Hospital of Sun Yat-Sen University
(January 2010 to December 2018) were retrospectively analyzed. All surgical procedures involved resection of at least two-thirds of the stomach with D2 lymph node dissection and were performed according to the guidelines of the Japanese Gastric Cancer Association [5]. No patients agreed to undergo ESD/EMR before the surgery. All clinicopathologic data, including age, sex, tumor location, tumor size, histological classification, lymphovascular invasion (LVI), depth of tumor invasion, and LNM, were collected from hospital and pathological records. Staging was performed according to the corresponding seventh edition of the AJCC Staging Manual [14]. Welland moderately differentiated tubular adenocarcinomas and papillary adenocarcinomas were grouped together as "differentiated lesions." Poorly differentiated adenocarcinomas and signet-ring cell carcinomas were classified as "undifferentiated histological types." Lesions with ulceration or scarring from previous ulceration (converging folds or deformity of the muscularis propria, or fibrosis in the submucosal or deeper layer) within them were regarded as "ulcerated lesions" [15]. This study was approved by the Ethics Committee of the First Affiliated Hospital of Sun Yat-sen University and conducted in accordance with the principles of the Declaration of Helsinki. The need for informed consent for participation and for approval of all patients was waived owing to the retrospective nature of the study and anonymized data.

\section{Inclusion and exclusion criteria}

The inclusion criteria were as follows: (1) the depth of invasion was diagnosed as carcinoma in situ (Tis), mucosa (T1a), or submucosa (T1b); and (2) absence of distant metastasis. Patients were excluded when they had (1) received neoadjuvant therapy or (2) incomplete clinicopathologic information (Fig. 1).

In total, 354 cases histologically proven to be Tis, $\mathrm{T} 1 \mathrm{a}$ or T1b following the inclusion and exclusion criteria were enrolled (Fig. 1). All patients were divided into the LNM+ group ( $n=65, \mathrm{LNM}+$ : presence of LNM) or LNM- group ( $n=289$, LNM-: absence of LNM). To analyze the LNM rate for the patients selected by the indications of ESD/EMR, all patients were also divided into four different groups according to the absolute and expanded indications of ESD/EMR. For submucosal invasive (T1b) EGC, the LNM status was analyzed according to two conditions $(\leq 2 \mathrm{~cm}$, differentiated type; $\leq 2 \mathrm{~cm}$, undifferentiated type).

\section{Follow-up examinations}

All patients included in this study were regularly followed up using a standardized protocol. Follow-up assessment included abdominal ultrasonography, computed tomography $(\mathrm{CT})$ imaging (of the chest, abdomen and pelvis), 


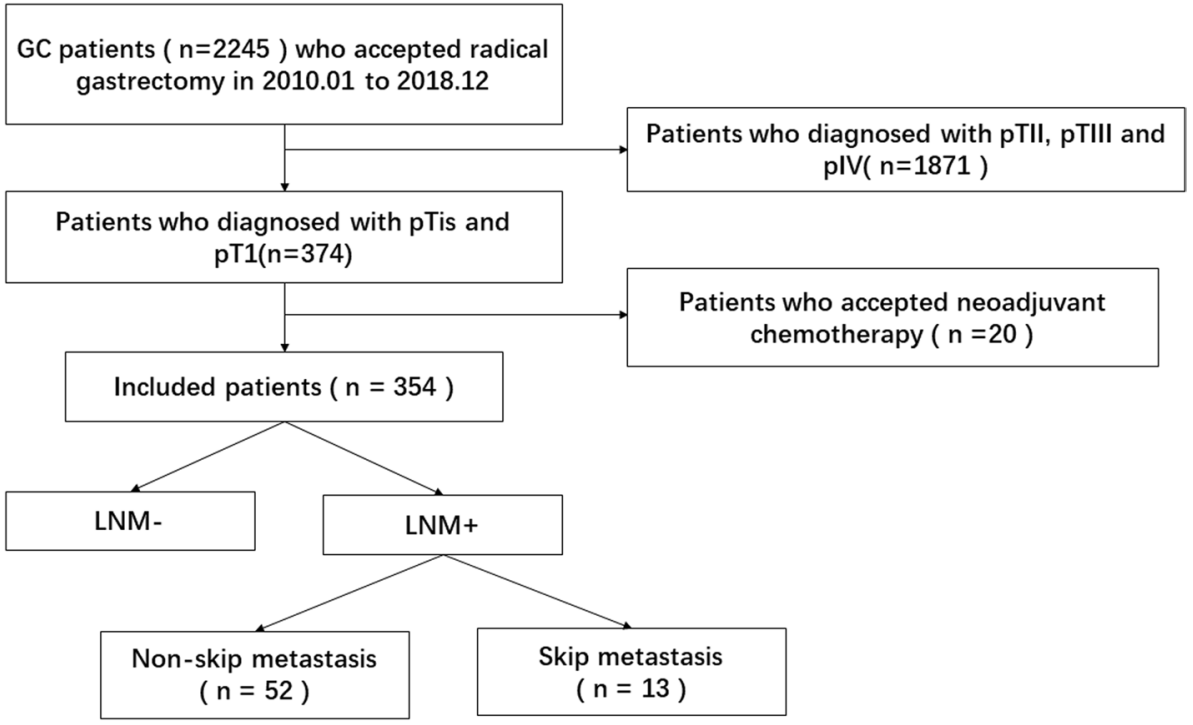

Fig. 1 Inclusion criteria for study participants. LNM-, absence of lymph node metastasis; LNM+, presence of lymph node metastasis

and tumor marker tests (including cancer antigen [CA]19-9, carcinoembryonic antigen [CEA], CA125, squamous cell carcinoma) at each visit.

Regarding the overall survival analysis, deaths due to any reasons were recorded as events. Regarding the disease-free survival analysis, deaths due to cancer were recorded as events, which were defined as postoperative recurrences at any site or cancer-related death. Deaths secondary to other causes, such as another disease or accident, were censored. Patients with unknown causes of death and their postoperative complications were excluded from the prognostic analysis.

\section{Statistical analysis}

All statistical analyses were conducted using the SPSS 24.0 statistical package (IBM Inc., Armonk, NY, USA) and R (https://www.r-project.org/; R Foundation for Statistical Computing, Vienna, Austria). Continuous variables are presented as the mean and standard deviation, and an analysis of variance test was used to compare continuous variables. For categorical variables, Pearson's chi-square or Fisher's exact test was used to compare the differences between the patient groups. Univariate and multivariate logistic regression models, in which all covariates were adjusted simultaneously, were used to determine independent risk factors for LNM. Kaplan-Meier curves were plotted to evaluate the survival outcomes in patients, and comparisons of prognostic differences between the patient groups were performed using the log-rank test. Independent prognostic factors were identified by multivariate analysis using the Cox proportional-hazard model with a stepwise selection procedure. Hazard ratios (HRs) and $95 \%$ confidence intervals (CIs) were calculated to quantify the relationship between the survival outcome and each clinicopathologic factor. Statistical significance was accepted at a $P$ value $<0.05$.

\section{Results}

\section{Clinicopathological characteristics of patients according to LNM}

The data of 2245 patients with GC who underwent radical gastrectomy with lymphadenectomy at the First Affiliated Hospital of Sun Yat-Sen University between January 1, 2010 and December 31, 2018 were reviewed retrospectively. In total, 354 cases histologically proven to be EGC or carcinoma in situ according to the inclusion and exclusion criteria were enrolled for the next analysis. As shown in Table 1, the current study consisted of 224 male (63.27\%) and 130 female patients (36.72\%), with a median age of $57.50 \pm 11.399$ years (range, $24-85$ years). Among these 354 patients, 35 (9.89\%), 165 (46.61\%), and 175 $(49.43 \%)$ patients had tumors located in the upper third, middle third, and lower third of the stomach, respectively. The mean length and short diameter of the tumor were $2.254 \pm 1.344 \mathrm{~cm}$ and $1.808 \pm 1.184 \mathrm{~cm}$, respectively. Postoperative pathology indicated LVI in 16 cases $(4.52 \%)$ and poorly differentiated tumors in 185 cases (52.26\%). The average number of lymph node dissections was $37.640 \pm 23.203$.

There were $61.86 \%(219 / 354)$ patients with intramucosal invasion (including Tis and T1a) and 38.14\% $(135 / 354)$ patients with submucosa (T1b) invasion. The 
Table 1 Clinicopathological characteristics in the LNM- $(n=289)$ and LNM+ groups $(n=65)$

\begin{tabular}{|c|c|c|c|c|c|}
\hline Factor & LNM- $(n=289)$ & $\mathrm{LNM}+(n=65)$ & LNM\% & Relative risk (Cl 95\%) & $P$-value \\
\hline Age (years) & $56.74 \pm 11.084$ & $54.80 \pm 12.677$ & & & 0.301 \\
\hline$<40$ & 16 & 10 & $38.46 \%$ & $2.297(1.333-3.947)$ & 0.006 \\
\hline$\geq 40$ & 273 & 55 & $16.77 \%$ & & \\
\hline Sex & & & & & 0.373 \\
\hline Male & 186 & 38 & $16.96 \%$ & & \\
\hline Female & 103 & 27 & $20.77 \%$ & & \\
\hline $\mathrm{BMI}\left(\mathrm{kg} / \mathrm{m}^{2}\right)$ & $21.08 \pm 5.914$ & $21.24 \pm 5.782$ & & & 0.874 \\
\hline \multicolumn{6}{|l|}{ Size $(\mathrm{cm})$} \\
\hline Length-diameter & $2.091 \pm 1.198$ & $2.930 \pm 1.689$ & & & 0.009 \\
\hline Short-diameter & $1.713 \pm 1.126$ & $2.196 \pm 1.342$ & & & 0.068 \\
\hline$<2 \mathrm{~cm}$ & 152 & 26 & $14.61 \%$ & $1.712(0.924-3.174)$ & 0.076 \\
\hline$\geq 2 \mathrm{~cm}$ & 137 & 39 & $22.16 \%$ & & \\
\hline$<3 \mathrm{~cm}$ & 236 & 39 & $14.18 \%$ & $2.496(1.532-4.065)$ & $<0.001$ \\
\hline$\geq 3 \mathrm{~cm}$ & 53 & 26 & $32.91 \%$ & & \\
\hline \multicolumn{6}{|l|}{ Tumor marker } \\
\hline CEA (U/mL) & $7.032 \pm 81.39$ & $4.394 \pm 9.618$ & & & 0.631 \\
\hline CA125 (U/mL) & $10.31 \pm 9.527$ & $9.995 \pm 5.774$ & & & 0.566 \\
\hline CA199 (U/mL) & $13.689 \pm 59.54$ & $17.703 \pm 45.017$ & & & 0.526 \\
\hline \multicolumn{6}{|l|}{ Location } \\
\hline Upper & 27 & 6 & $18.18 \%$ & & 0.765 \\
\hline Middle & 136 & 28 & $17.07 \%$ & & \\
\hline Lower & 142 & 31 & $17.92 \%$ & & \\
\hline \multicolumn{6}{|l|}{ Depth of invasion } \\
\hline Tis & 41 & 1 & $2.38 \%$ & & $<0.001$ \\
\hline T1a & 152 & 25 & $14.12 \%$ & & \\
\hline $\mathrm{T} 1 \mathrm{~b}$ & 98 & 37 & $27.41 \%$ & & \\
\hline \multicolumn{6}{|l|}{ Differentiation } \\
\hline Well/Moderate & 155 & 14 & $8.28 \%$ & & $<0.001$ \\
\hline Poorly & 134 & 51 & $27.57 \%$ & $3.328(1.914-5.787)$ & \\
\hline \multicolumn{6}{|l|}{ Ulcer finding } \\
\hline Absent & 133 & 36 & $21.30 \%$ & & 0.172 \\
\hline Present & 156 & 29 & $15.68 \%$ & & \\
\hline Number of lymph nodes & $36.97 \pm 24.157$ & $40.63 \pm 18.23$ & & & 0.864 \\
\hline \multicolumn{6}{|l|}{ LVI } \\
\hline Absent & 283 & 55 & $16.27 \%$ & & $<0.001$ \\
\hline Present & 6 & 10 & $62.5 \%$ & $3.751(2.422-5.809)$ & \\
\hline Recurrence & 7 & 2 & & & \\
\hline OS rate ${ }^{a}$ & $94.54 \%$ & $80.77 \%$ & & & 0.021 \\
\hline DFS rate ${ }^{a}$ & $93.64 \%$ & $79.17 \%$ & & & 0.011 \\
\hline
\end{tabular}

$B M I$ body mass index, $L N M$ lymph node metastasis, $L V I$ lymphovascular invasion, $L N M$ - absence of lymph node metastasis, $L N M+$ presence of lymph node metastasis, Cl confidence interval, CEA carcinoembryonic antigen, CA125 cancer antigen 125, CA199 cancer antigen 199, OS overall survival, DFS disease-free survival

a The 5-year survival rate refers to the survival status of patients treated with surgery between January 2010 and March 2015 . The OS rates were as follows: LNM-, 104/107 (94.54\%); LNM+, 20/24 (80.77\%). The DFS rates were as follows: LNM-, 103/107 (96.26\%); LNM+, 19/24 (79.17\%)

percentages of LNM positivity was $27.41 \%(37 / 135)$ in the submucosa group $(P<0.001)$. Meanwhile, the percentages of LNM positivity were $2.38 \%(1 / 42)$ in the Tis groups and $14.12 \%(25 / 177)$ in the T1a groups. There was no significant difference in the mean age of patients between the two groups, but there was a significant difference between those aged $<40$ and $\geq 40$ years $(P=0.006)$, suggesting that younger patients have a higher risk of presenting LNM (risk ratio $[\mathrm{RR}]=2.297$; 95\% CI, 1.3333.947). Tumor sizes were significantly larger for LNM+ 
than for LNM- cases $(P=0.009)$. Compared with those with LNM-, tumor invasion was deeper $(P<0.001$; $\mathrm{RR}=2.256$; 95\% CI, 1.447-3.518) and showed poor differentiation $(\mathrm{P}<0.001$; $\mathrm{RR}=3.328$; 95\% CI, 1.914-5.787) in those with LNM+. However, the distribution of other variables including sex, body mass index, tumor maker, and tumor location were similar between the LNM- and LNM+ groups.

\section{Metastasis status of different lymph node groups in patients}

In this study, the incidence of LNM in these patients was $18.36 \%$ (65/354). To further elucidate the role of LNM in EGC, we analyzed the positive rate (Table 2) and location distribution (Table 3) of LNM for each lymph node station. As shown in Table 2, the positive rates of No. 3, 4, and 6 lymph nodes were 4.80, 3.67, and 3.95\%, respectively, regardless of the tumor location. For tumors located in the upper-third of the stomach with LNM $(n=6)$, the No. 2 and 3 lymph nodes had high positive rates of LNM (Table 3). For tumors in the middle-third of the stomach $(n=28)$, No. 3, 4, 5, and 6 lymph nodes had the highest positive rates of LNM. For tumors in the lower third of the stomach, No. 3 and 6 lymph node stations had the highest metastasis rates.

\section{Univariable and multivariable analysis of LNM}

The univariable analysis showed that LNM was closely related to age $(<40$ years $)$, tumor size $(>3 \mathrm{~cm})$, depth of invasion (T1b), poor differentiation, and LVI (all $P<0.05$; Table 4). Multivariate analysis showed that tumor size (odds ratio $[\mathrm{OR}]=2.948$; $95 \% \mathrm{CI}, 1.480-5.872$; $P=0.002)$, poor differentiation $(\mathrm{OR}=5.879$; $95 \% \mathrm{CI}$, 2.536-13.628; $P=0.001)$, and LVI $(\mathrm{OR}=14.569 ; 95 \% \mathrm{CI}$,

Table 2 Positive rate of each lymph node station in all patients $(n=354)$

\begin{tabular}{ccllll}
\hline Station & Case & Positive rate & Station & Case & Positive rate \\
\hline No. 1 & 9 & $2.54 \%$ & No. 7 & 10 & $2.82 \%$ \\
No. 2 & 2 & $0.56 \%$ & No. 8 & 6 & $1.69 \%$ \\
& & & No. $8 \mathrm{a}$ & 5 & $1.41 \%$ \\
& & & No. $8 \mathrm{p}$ & 1 & $0.28 \%$ \\
No. 3 & 17 & $4.80 \%$ & No. 9 & 2 & $0.56 \%$ \\
No. 4 & 13 & $3.67 \%$ & No. 10 & 1 & $0.28 \%$ \\
No. $4 \mathrm{sa}$ & 6 & $1.69 \%$ & & & \\
No. 4sb & 4 & $1.13 \%$ & & & \\
No. 4sd & 4 & $1.13 \%$ & No. 11 & 2 & $0.56 \%$ \\
No. 5 & 11 & $3.11 \%$ & No. 11p & 1 & $0.28 \%$ \\
No.6 & 14 & $3.95 \%$ & No. 11d & 1 & $0.28 \%$ \\
& & & No. 12 & 3 & $0.85 \%$ \\
\hline
\end{tabular}

Table 3 Distribution of LNM in each station according to tumor location

\begin{tabular}{llll}
\hline Station & $\begin{array}{l}\text { Upper }(\boldsymbol{n}=\mathbf{6} \\
\text { cases })\end{array}$ & $\begin{array}{l}\text { Middle }(\boldsymbol{n}=\mathbf{2 8} \\
\text { cases })\end{array}$ & $\begin{array}{l}\text { Lower } \\
(\boldsymbol{n}=\mathbf{3 1} \\
\text { cases })\end{array}$ \\
\hline No. 1 & 1 & 3 & 4 \\
No. 2 & 2 & 0 & 0 \\
No. 3 & 2 & 8 & 7 \\
No. 4 & 1 & 7 & 5 \\
No. 5 & 0 & 5 & 6 \\
No. 6 & 0 & 7 & 7 \\
No. 7 & 1 & 3 & 6 \\
No. 8 & 0 & 1 & 4 \\
No. $8 a$ & 0 & 1 & 4 \\
No. $8 p$ & 0 & 0 & 0 \\
No. 9 & 0 & 0 & 1 \\
No. 10 & 0 & 0 & 1 \\
No. 11 & 1 & 1 & 0 \\
No. 11p & 1 & 0 & 0 \\
No. 11d & 0 & 1 & 0 \\
No. 12 & 1 & 1 & 1 \\
\hline
\end{tabular}

LNM lymph node metastasis

2.493-85.135; $P=0.001)$ were independent predictors for LNM (Table 4). However, age and depth of invasion were not independent predictors of LNM. The receiver operating characteristic (ROC) curve (Fig. 2) was used to validate this multivariable regression model. This model showed an area under the curve (AUC) of 0.782. Figure 3 presents a nomogram for the prediction of LNM that was constructed based on the selected variables.

\section{Correlation factors analysis of the extent of LNM}

The rates of D1 and D2 station metastases in patients were $12.10 \%(43 / 354)$ and $6.21 \%(22 / 354)$, respectively (Table 5). An analysis of the clinical pathological characteristics was performed on patients with D1 or D2 station LNM. There was no significant difference between the occurrence of D2 station LNM and the age, sex, tumor size, differentiation, location, depth of tumor invasion, and LVI. The levels of CA 19-9 and CEA were significantly different between the two groups (10.113 vs. $30.125 \mathrm{U} / \mathrm{mL}, P=0.001 ; 3.189$ vs. $6.861 \mathrm{U} / \mathrm{mL} ; P=0.003$ ). However, the difference in CA 125 was not significant (Table 5).

\section{Analysis of the clinicopathological characteristics of patients with skip metastasis}

According to the Japanese classification of gastric carcinoma (3rd edition) [16] and the definition of skip metastasis, patients with LNM $(n=65)$ were classified into the no skip metastasis $(n=52)$ or the skip metastasis group 
Table 4 Univariable and multivariable analyses for LNM

\begin{tabular}{|c|c|c|c|c|}
\hline \multirow[t]{2}{*}{ Factor } & \multicolumn{2}{|l|}{ Univariable analysis } & \multicolumn{2}{|l|}{ Multivariable analysis } \\
\hline & OR $(95 \% \mathrm{Cl})$ & $P$-value & OR $(95 \% \mathrm{Cl})$ & $P$-value \\
\hline \multicolumn{5}{|l|}{ Age (years) } \\
\hline$<40$ & 1 & & & \\
\hline$\geq 40$ & $0.322(0.139-0.748)$ & 0.008 & NA & NA \\
\hline \multicolumn{5}{|l|}{ Tumor size } \\
\hline$<3 \mathrm{~cm}$ & 1 & & & \\
\hline$\geq 3 \mathrm{~cm}$ & $3.230(1.710-6.101)$ & $<0.001$ & $2.948(1.480-5.872)$ & 0.002 \\
\hline \multicolumn{5}{|l|}{ Depth of invasion } \\
\hline Mucosal & 1 & & & \\
\hline Submucosa & $2.743(1.583-4.755)$ & $<0.001$ & NA & NA \\
\hline \multicolumn{5}{|l|}{ Ulcer } \\
\hline Absent & 1 & & & \\
\hline Present & $0.687(0.400-1.180)$ & 0.173 & NA & NA \\
\hline \multicolumn{5}{|l|}{ Differentiation } \\
\hline Well/Moderate & 1 & & & \\
\hline Poorly & $4.214(2.233-7.951)$ & $<0.001$ & $5.879(2.536-13.628)$ & 0.001 \\
\hline \multicolumn{5}{|l|}{ LVI } \\
\hline Absent & 1 & & & \\
\hline Present & $8.576(2.993-24.568)$ & $<0.001$ & $14.569(2.493-85.135)$ & 0.001 \\
\hline
\end{tabular}

$O R$ odds ratio, $C I$ confidence interval, $L V I$ lymphovascular invasion, $N A$ not applicable

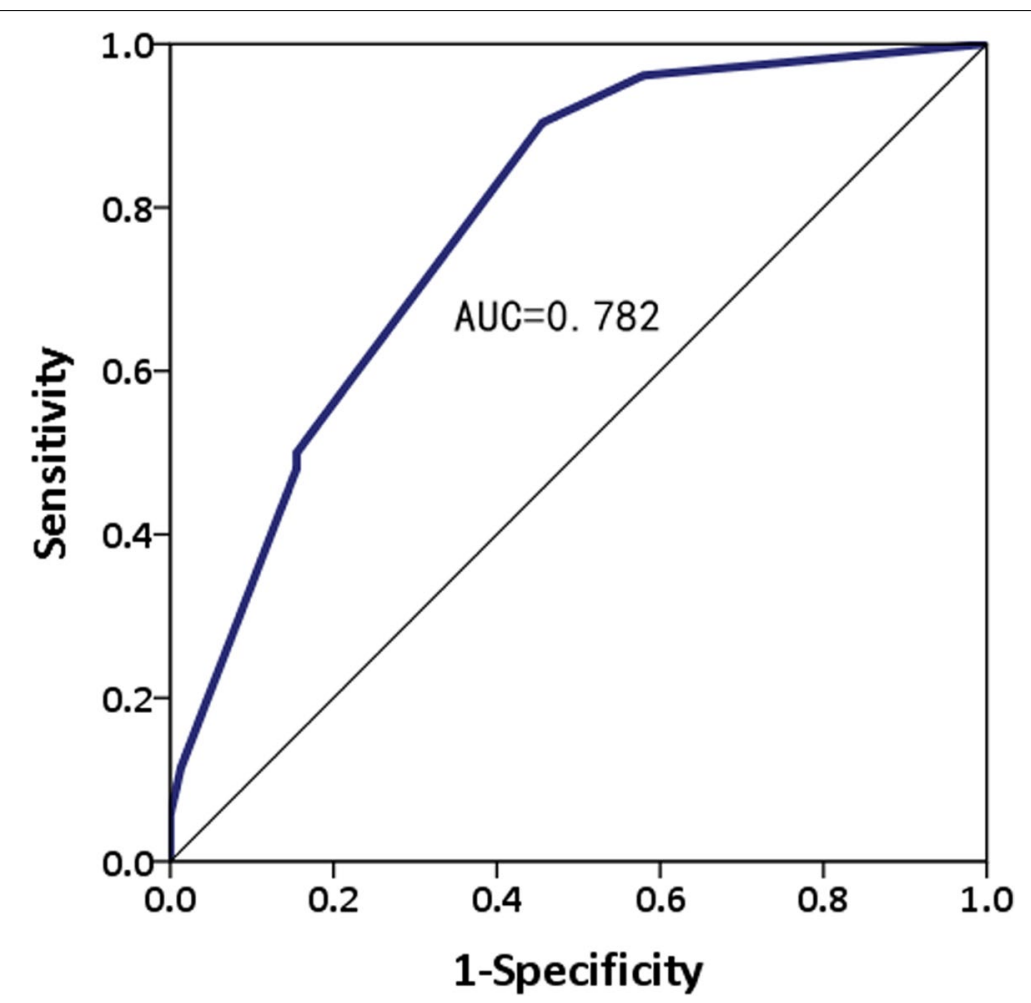

Fig. 2 ROC curve of the multivariable model for predicting LNM. ROC, receiver operating characteristic; LNM, lymph node metastasis 


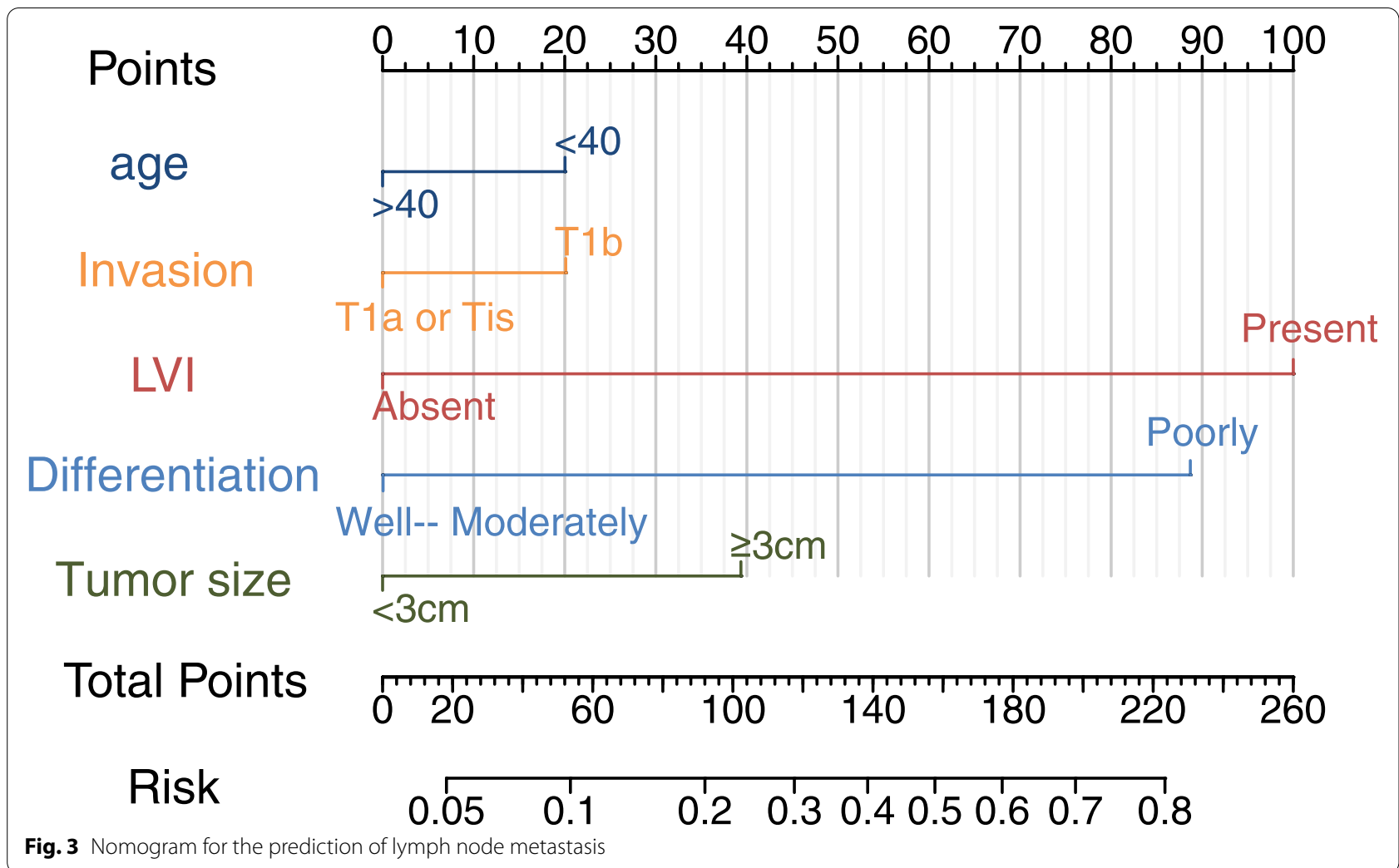

$(n=13)$. The possibility of skip metastasis was $3.67 \%$ $(13 / 354)$ in all patients. There was no significant difference between the two groups with respect to clinicopathological characteristics (Table 6).

\section{Univariate and multivariate analyses of prognostic factors in patients}

The 5-year overall survival rates in the LNM- and LNM+ groups were 97.19 and $83.33 \%$, respectively $(P=0.021)$. Moreover, the disease-free survival rates in the LNM - and LNM+ groups were 96.26 and 79.17\%, respectively $(P=0.011$; Table 1$)$. The prognostic outcome of patients who were LNM+ was worse than that of LNM- patients $(P=0.008)$ (Fig. 4). The results of the univariate and multivariate analyses for prognostic factors are presented in Table 7. Tumor size (HR, 3.473; 95\% CI, 1.372-8.791; $P=0.009)$ and LNM (HR, 4.895; 95\% CI, 1.588-15.095; $P=0.006)$ were independent predictive factors for poor survival outcome in all patients.

\section{LNM rate in patients selected by the indications of ESD/ EMR}

The 2018 Japanese GC treatment guidelines [5] revealed that the indication for ER depends on the depth of invasion, differentiation type, diameter, and ulcerative findings. The LNM rates of these factors are demonstrated in Table 1 . The data of all patients $(n=354)$ were analyzed according to the absolute and expanded indications of ESD/EMR (Table 8), and only 75 (21.18\%) patients conformed to the absolute and expanded indications of ESD/EMR. The rates of LNM in absolute and expanded indications were $2 / 61$ (3.27\%) and 4/14 (28.57\%), respectively. Subgroup analysis showed that the rates of LNM with respect to the absolute indication of EMR/ESD and absolute indication of the ESD 2 group were $0 \%$. The rate of LNM with respect to the absolute indication of the ESD 1 group was $20 \%$. For the submucosal invasive (T1b) EGC, the LNM status was analyzed with two conditions ( $\leq 2 \mathrm{~cm}$, differentiated type: $7.40 \% ; \leq 2 \mathrm{~cm}$, undifferentiated type: $34.375 \%$ ), which was consistent with the outcome of the multivariable logistic analysis (Table 4).

\section{Discussion}

EGC was first defined in 1962 by the Japanese Research Society for Gastric Cancer as tumors with invasion limited to the mucosa or submucosa of the stomach, irrespective of lymph node involvement. In the 8th American Joint Committee on Cancer TNM staging system, EGC corresponds to GC with Tis, T1a (mucosa), and T1b (submucosa) stages [17]. Recently, the treatment techniques and strategies for EGC have been updated rapidly. According to the latest Japanese GC treatment 
Table 5 Clinicopathological characteristics of the patients with D1 $(n=43)$ and D2 station metastasis $(n=22)$ set

\begin{tabular}{|c|c|c|c|}
\hline Factor & D1 station ${ }^{a}$ & D2 station ${ }^{\mathrm{a}}$ & $P$-value \\
\hline \multicolumn{4}{|l|}{ Age (years) } \\
\hline$<40$ & 37 & 18 & 0.655 \\
\hline$\geq 40$ & 6 & 4 & \\
\hline \multicolumn{4}{|l|}{ Sex } \\
\hline Male & 26 & 12 & 0.647 \\
\hline Female & 17 & 10 & \\
\hline \multicolumn{4}{|l|}{ Tumor size } \\
\hline Length-diameter $(\mathrm{cm})$ & 2.938 & 2.917 & 0.295 \\
\hline Short-diameter (cm) & 2.303 & 2.000 & 0.243 \\
\hline$<2 \mathrm{~cm}$ & 9 & 2 & 0.163 \\
\hline$\geq 2 \mathrm{~cm}$ & 23 & 16 & \\
\hline$<3 \mathrm{~cm}$ & 16 & 8 & 0.706 \\
\hline$\geq 3 \mathrm{~cm}$ & 16 & 10 & \\
\hline \multicolumn{4}{|l|}{ Tumor marker } \\
\hline CEA $(U / m L)$ & 3.189 & 6.861 & 0.003 \\
\hline CA125 (U/mL) & 9.702 & 10.568 & 0.165 \\
\hline CA199 (U/mL) & 10.113 & 30.125 & 0.001 \\
\hline Tumor location & & & 0.171 \\
\hline Upper & 3 & 3 & \\
\hline Middle & 22 & 6 & \\
\hline Lower & 18 & 13 & \\
\hline Depth of invasion & & & 0.322 \\
\hline Intra-mucosal & 16 & 11 & \\
\hline Submucosa & 27 & 11 & \\
\hline \multicolumn{4}{|l|}{ Differentiated } \\
\hline Well-Moderately & 8 & 6 & 0.421 \\
\hline Poorly & 35 & 16 & \\
\hline \multicolumn{4}{|l|}{ LVI } \\
\hline Absent & 48 & 10 & 0.940 \\
\hline Present & 9 & 2 & \\
\hline
\end{tabular}

For total gastrectomy: D1: Nos. 1-7; D1+: D1 + Nos. 8a, 9, 11 p; D2: D1 + Nos. 8a, 9, 11p, 11d, 12a

For distal gastrectomy: D1: Nos. 1, 3, 4sb, 4d, 5, 6, 7; D1+:D1 + Nos. 8a, 9; D2: D1 + 8a, 9, 11p, 12a

For pylorus-preserving gastrectomy: D1: Nos. 1, 3, 4sb, 4d, 6, 7; D1+: Nos. 8a, 9

For proximal gastrectomy: D1: Nos. 1, 2, 3s, 4sa, 4sb, 7; D1+: D1 + Nos. 8a, 9, 11p LVI lymphovascular invasion, CEA carcinoembryonic antigen, CA125 cancer antigen 125, CA199 cancer antigen 199

${ }^{a}$ According to the Japanese gastric cancer treatment guidelines 2018 (5th edition)

guidelines (5th version) [5], EMR or ESD is considered a standard treatment for patients with EGC with absolute indications and an alternative treatment for EGC with expanded indications. With the development and prevalence of ER (ESD and EMR), the criteria for the indications of ER for EGC have continually expanded. However, there is a debate as to whether ER can be used in patients with expanded indications.
Table 6 Clinicopathological characteristics of patients with LNM without $(n=52)$ and with skip metastasis $(n=13)$

\begin{tabular}{|c|c|c|c|}
\hline Factor & $\begin{array}{l}\text { Without skip } \\
\text { metastasis }\end{array}$ & $\begin{array}{l}\text { With skip } \\
\text { metastasis }\end{array}$ & $P$-value \\
\hline \multicolumn{4}{|l|}{ Age (years) } \\
\hline$<40$ & & 4 & 0.086 \\
\hline$\geq 40$ & & 9 & \\
\hline \multicolumn{4}{|l|}{ Sex } \\
\hline Male & 33 & 5 & 0.102 \\
\hline Female & 19 & 8 & \\
\hline \multicolumn{4}{|l|}{ Size } \\
\hline Length-diameter (cm) & 2.950 & 2.750 & 0.358 \\
\hline Short-diameter (cm) & 2.305 & 1.786 & 0.452 \\
\hline$<2 \mathrm{~cm}$ & 9 & 2 & 0.729 \\
\hline$\geq 2 \mathrm{~cm}$ & 30 & 9 & \\
\hline$<3 \mathrm{~cm}$ & 20 & 4 & 0.382 \\
\hline$\geq 3 \mathrm{~cm}$ & 19 & 7 & \\
\hline Tumor Location & & & 0.054 \\
\hline Upper & 5 & 1 & \\
\hline Middle & 26 & 2 & \\
\hline Lower & 21 & 10 & \\
\hline \multicolumn{4}{|l|}{ Depth of invasion } \\
\hline Mucosal & 20 & 7 & 0.314 \\
\hline Submucosa & 32 & 6 & \\
\hline \multicolumn{4}{|l|}{ Differentiated } \\
\hline Well-Moderately & 11 & 3 & 0.880 \\
\hline Poorly & 41 & 10 & \\
\hline \multicolumn{4}{|l|}{ LVI } \\
\hline Absent & 45 & 13 & 0.726 \\
\hline Present & 8 & 3 & \\
\hline
\end{tabular}

LNM lymph node metastasis

Interestingly, the 2018 Japanese GC treatment guidelines declared that the possibility of harboring LNM in the tumor with absolute indication is $<1 \%$. However, most of the data referred to were obtained from Japanese patients [5]. It remains unclear whether the data can be extrapolated to cases from other countries. Some studies from Western countries revealed that the LNM rate of some racial/ethnic groups is almost double that of Asian patients with T1a GC $[18,19]$. Here, we revealed that the incidence of LNM in patients with EGC, which confirmed the absolute or expanded indications of ESD/EMR, was obviously higher than that in the Japanese cohort [4, 20-22]. The rates of LNM in the absolute indication of the ESD 1 group $(2 / 10,20 \%)$ and the expanded indication group $(4 / 14,28.57 \%)$ were obviously $>1 \%$. Moreover, a meta-review [4] published in 2018 indicated that the incidence rate of LNM was 2.6\% (25/972) in patients who met the expanded criteria. Moreover, a Korean study [23] in 2020 reported that LNMs were found in 6.7\% $(18 / 270)$ of patients with undifferentiated-type EGC who 


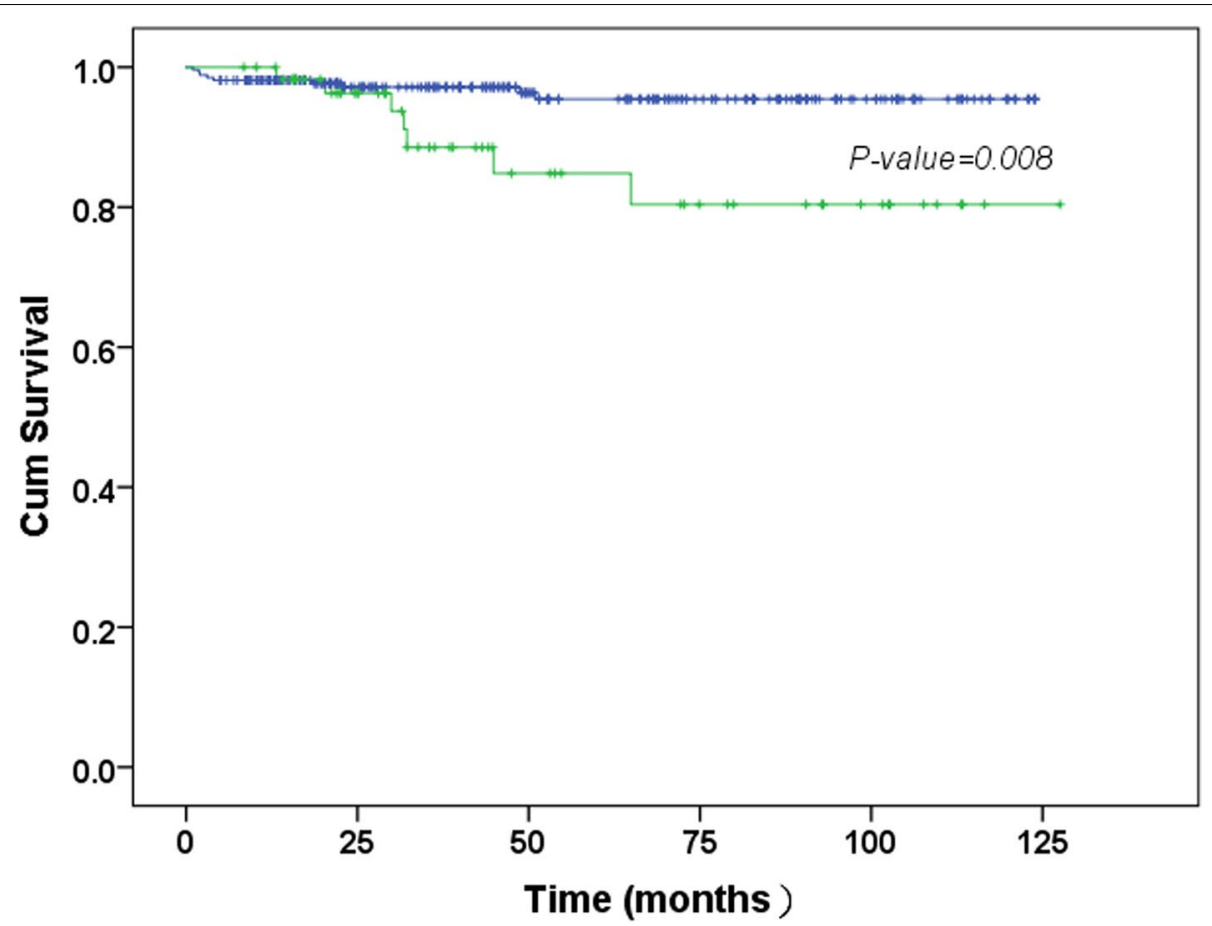

Fig. 4 Kaplan-Meier curve of cumulative survival of patients with LNM+ (green) and LNM- (blue). LNM, lymph node metastasis; LNM-, absence of lymph node metastasis; LNM+, presence of lymph node metastasis; $X$-axis represents the survival time; $Y$-axis represents the survival rate

Table 7 Univariate and multivariate analyses of prognostic factors

\begin{tabular}{|c|c|c|c|c|}
\hline \multirow[t]{2}{*}{ Factor } & \multicolumn{2}{|l|}{ Univariable analysis } & \multicolumn{2}{|l|}{ Multivariable analysis } \\
\hline & HR (Cl 95\%) & $P$-value & HR (Cl 95\%) & $P$-value \\
\hline \multicolumn{5}{|l|}{ Age (years) } \\
\hline$<40$ & 1 & & & \\
\hline$\geq 40$ & $1.067(0.141-8.076)$ & 0.950 & NA & NA \\
\hline \multicolumn{5}{|l|}{ Tumor size } \\
\hline$<2 \mathrm{~cm}$ & 1 & & & \\
\hline$\geq 2 \mathrm{~cm}$ & $2.791(0.937-8.317)$ & 0.065 & $3.473(1.372-8.791)$ & 0.009 \\
\hline$<3 \mathrm{~cm}$ & 1 & & & \\
\hline$\geq 3 \mathrm{~cm}$ & $1.593(0.438-5.792)$ & 0.480 & NA & NA \\
\hline \multicolumn{5}{|l|}{ Depth of invasion } \\
\hline Mucosal & 1 & & & \\
\hline Submucosa & $1.178(0.426-3.259)$ & 0.753 & NA & NA \\
\hline \multicolumn{5}{|l|}{ Differentiation } \\
\hline Well-Moderately & 1 & & & \\
\hline Poorly & $1.425(0.531-3.828)$ & 0.482 & NA & NA \\
\hline \multicolumn{5}{|l|}{ LVI } \\
\hline Absent & 1 & & & \\
\hline Present & 2.419 (0.310-18.885) & 0.399 & NA & NA \\
\hline \multicolumn{5}{|l|}{ LNM } \\
\hline Absent & 1 & & & \\
\hline Present & $3.512(1.307-9.438)$ & 0.013 & 4.895 (1.588-15.095) & 0.006 \\
\hline
\end{tabular}


Table 8 LNM rate of patients selected by the indications of ESD/ EMR

\begin{tabular}{llll}
\hline Conditions & LNM- & LNM+ & Metastasis rate \\
\hline Absolute indication of EMR or ESD $^{\mathrm{a}}$ & 22 & 0 & $0 \%$ \\
Absolute indication of ESD 1 $^{\mathrm{a}}$ & 8 & 2 & $20 \%$ \\
Absolute indication of ESD 2 $^{\mathrm{a}}$ & 29 & 0 & $0 \%$ \\
Expanded indication $^{\mathrm{a}}$ & 10 & 4 & $28.57 \%$ \\
$\mathrm{~T}_{1} \mathrm{~b}, \leq 2 \mathrm{~cm}$, differentiated-type & 25 & 2 & $7.40 \%$ \\
$\mathrm{~T}_{1} \mathrm{~b}, \leq 2 \mathrm{~cm}$, undifferentiated-type & 21 & 11 & $34.375 \%$ \\
\hline
\end{tabular}

Absolute indication of ESD 1: A differentiated-type adenocarcinoma without ulcerative findings, in which the depth of invasion is clinically diagnosed as T1a and the diameter is $>2 \mathrm{~cm}$

Absolute indication of ESD 2: A differentiated-type adenocarcinoma with ulcerative findings, in which the depth of invasion is clinically diagnosed as T1a and the diameter is $\leq 3 \mathrm{~cm}$

Expanded indication: An undifferentiated-type adenocarcinoma without ulcerative findings in which the depth of invasion is clinically diagnosed as T1a and the diameter is $\leq 2 \mathrm{~cm}$

LNM lymph node metastasis, LNM- absence of lymph node metastasis, $L N M+$ presence of lymph node metastasis, EMR endoscopic mucosal resection, ESD endoscopic submucosal dissection

${ }^{\text {a }}$ Absolute indication of EMR or ESD: A differentiated-type adenocarcinoma without ulcerative findings (ULO), in which the depth of invasion is clinically diagnosed as T1 a and the diameter is $\leq 2 \mathrm{~cm}$

underwent additional surgery after non-curative endoscopic resection. Therefore, caution should be exercised before applying ESD to patients with undifferentiatedtype adenocarcinoma and those with tumors $>2 \mathrm{~cm}$ despite having T1a and differentiated-type adenocarcinoma without ulcerative findings. Further studies are urgently needed to find new methods to distinguish populations with high risk of LNM from EGC conforming to the indications of ER.

It is worth mentioning that the sample size of this study was small. We screened for desirable cases from 2245 patients with GC. However, only $15.77 \%$ of patients with GC were diagnosed with EGC in our center. The data were consistent with the results reported from other centers in China. The proportion of cases of EGC in China varied from 10 to $20 \%$, compared to approximately $50 \%$ in Japan $[24,25]$. Moreover, only $21.18 \%$ of patients conformed to the absolute and expanded indications of ESD/EMR in this study. The numbers of cases in the confirmed ESD $1(n=10)$ and expanded indication $(n=14)$ groups were too small to achieve the desired result. However, a Chinese study in 2016 also reported that the LNM rate was as high as $8.70 \%$ when the Japanese expanded criteria were used [26]. Another study reported that the rate of LNM was high $(8.00-14.30 \%)$ when tumors were $>30 \mathrm{~mm}$ in diameter for patients with T1a stage EGC [27]. Therefore, our data suggested that ESD/EMR treatment of EGC should be considered carefully in different racial populations [19], and more data are needed to draw a firm conclusion about the expanded indication for ESD.

The Japanese Gastric Cancer Association guidelines suggested a gastrectomy procedure with $\mathrm{D} 1 / \mathrm{D} 1+$ lymph node dissection as the standard surgical procedure for cases, in which the depth of invasion is clinically diagnosed as T1b without LNM and T1a without LNM, which do not allow the performance of EMR and ESD. However, our data showed that the rate of D2 station LNM was $6.21 \%$. For these cases, the D1 or D1+ dissection is not sufficient. Furthermore, skip LNM is another factor influencing the determination of the extent of lymph node dissection.

Skip metastasis in GC refers to the presence of extraperigastric LNM without perigastric lymph node involvement [10]. There have been few studies on the phenomenon of jump metastasis and its related mechanism in patients with GC, especially in those with EGC [9-13, 28]. The incidence of skip metastasis in patients with LNM in EGC has been reported to range from 2.7 to $21.6 \%[10,28,29]$. In this study, the incidence of skip metastasis in patients with LNM was $3.67 \%$ (13/354), which is consistent with prior research results. Liu et al. [9] revealed that tumor size was the only clinicopathologic factor that could predict lymph node skip metastasis in patients with $\mathrm{N} 1$ stage cancer (the number of metastatic lymph nodes among the regional lymph nodes is 1-2) undergoing radical surgery. However, no significant related clinical characteristics were found for skip metastasis in our study. Considering the relatively high incidences of D2 LNM and skip LNM in EGC, it is not suitable for these patients to receive D1 or D1+ dissection. Therefore, the identification of these high-risk portions from EGC is urgently needed so that the patients can undergo radical lymphadenectomy.

Regarding the extent of gastric resection, the Japanese GC treatment guidelines have revealed that the standard surgical procedure for $\mathrm{cN}+$ or T2-T4a tumor is total or distal gastrectomy. For cT1N0 tumors, PPG and proximal gastrectomy can be considered depending on the tumor position. PPG is a less-invasive function-preserving procedure that has been applied for the cT1N0M0 middle-third EGC with a distal tumor border at least $4 \mathrm{~cm}$ proximal to the pylorus according to the Japanese GC treatment guidelines [5]. The survival and recovery benefits of PPG have already been reported in several retrospective studies [30-32]. However, the performance of PPG remains controversial. One of the reasons is that the dissection of the No. 5 lymph node may be incomplete when performing PPG because the pyloric branches of the vagus nerve are kept to reduce the postoperative gastric stasis complications. A previous study reported that the metastasis rate of No. 5 lymph node in middle-third 
EGC was only $0.5 \%$ [33]. Kong et al. [34] reported that the metastasis rates of the No. 5 lymph node in middle-third EGC with a distal tumor border at least $6 \mathrm{~cm}$ proximal to the pylorus were $0 \%$ in T1a stage and $0.9 \%$ in T1b stage EGC. However, the metastasis rate of the No. 5 lymph node was $3.03 \%$ (5/165) for the middle-third EGC in this study (Table 2 and Table 3), which was similar to the result of Seung et al. [35], who reported that the metastasis rate to the No. 5 lymph nodes was $4.2 \%$ (52/1245). Seung et al. [35] also pointed out that the presence or absence of metastasis in the No. 5 and No. 6 lymph nodes should be carefully evaluated preoperatively using endoscopic ultrasonography and CT. Therefore, caution should be exercised before performing PPG for EGC given that the risk of No. 5 LNM is high according to our data. Further prospective studies using large case series are necessary to confirm this conclusion. It is worth mentioning that PPG should be performed for GC located in the middle third of the stomach and at least $4.0 \mathrm{~cm}$ away from the pylorus according to the guidelines. However, information about the distance from the tumor to the pylorus was unavailable in our database. This limitation weakened our conclusion.

LNM is one of the most important factors influencing the prognosis of EGC. The risk of LNM is a major concern when choosing the optimal treatment for EGC. According to previous studies, the incidence of LNM in patients with EGC, regardless of $\mathrm{T} 1 \mathrm{a}$ or $\mathrm{T} 1 \mathrm{~b}$ diagnosis, was $15-24 \%$ [36, 37]. Recently, Chen et al. reported that the LNM rate was $16.7 \%$ in EGC (8.7\% in T1a, $24.6 \%$ in $\mathrm{T} 1 \mathrm{~b})$ in their retrospective study that enrolled 1033 patients with EGC [38]. In agreement with results of previously reported studies, our data showed that the incidence rates of LNM were $12.38 \%$ in T1a stage, $27.94 \%$ in T1b stage, and $18.36 \%$ in whole EGC. Classifying the low and high risks of LNM in patients with EGC is important in EGC studies.

A number of studies have identified the risk factors associated with LNM in EGC [28, 39-43]. They also revealed that $\mathrm{LNM}$ in EGC is related to differentiation, tumor size, depth of invasion, and LVI, which is consistent with the results of this study (Table 4).

The AUC of the ROC curve (Fig. 2), which validated this multivariable regression model, was 0.783 in this study. In other studies on the prediction of LNM with clinicopathological characteristics, the AUCs of the ROC curves were approximately 0.69-0.86 [40, 44, 45]. Similarly, the 2018 Japanese GC treatment guidelines [5] predicted the risk of LNM in EGC according to the clinicopathological characteristics including histological types (ulcerative findings), and tumor sizes $<2 \mathrm{~cm}$ (non-ulcerative) and $<3 \mathrm{~cm}$ (ulcerative). However, the prediction of LNM in EGC by these factors is still not ideal given that the incidence risk of LNM was high in the population of patients with EGC with absolute or expanded indication, as shown in this study. The prediction of LNM in EGC based only on the current routine detection items and pathological examination may not be reliable. Hence, the discovery of more factors that could more accurately predict LNM remains a research interest in the field of EGC. Finally, this study also analyzed the prognosis of patients with EGC and revealed that those with LNM had a worse prognosis (Fig. 4).

\section{Conclusions}

In summary, the risks of LNM were high in patients with EGC with undifferentiated-type adenocarcinoma and in those with a $>2-\mathrm{cm}$ tumor and expanded indications of ER. In addition, PPG remains controversial due to the high metastasis rate of the No. 5 lymph node in patients with middle-third tumor. Hence, physicians should be cautious when choosing a minimally invasive treatment (e.g., EMR, ESD, or PPG) that could carry a risk if the dissection of metastatic lymph nodes is neglected.

\section{Abbreviations \\ EGC: Early gastric cancer; GC: Gastric cancer; LNM: Lymph node metastasis; LVI: Lymphovascular invasion; EMR: Endoscopic mucosal resection; ESD: Endoscopic submucosal dissection; PPG: Pylorus-preserving gastrectomy; CA: Cancer antigen; CEA: Carcinoembryonic antigen; HR: Hazard ratio; Cl: Confi- dence interval; OR: Odds ratio; ER: Endoscopic resection; RR: Risk ratio; ROC: Receiver operating characteristic; AUC: Area under the curve; CT: Computed tomography.}

\section{Acknowledgements}

Not applicable.

\section{Authors' contributions}

WYZ and WZX extracted the data from and wrote the draft. WYX, WZX, ZZH, and LGH performed the analysis. WYZ and WZ designed the project. WZ and $L G H$ revised the project. All authors have read and approved the final manuscript.

\section{Funding}

This study was funded by the Natural Science Foundation of Guangdong Province, China (Grant Nos. 2016A030310155, 2017A030313577, and 2018A030313978) and the National Natural Science Foundation of China (Grant Nos. 81602049 and 81802342).

\section{Availability of data and materials}

The datasets used and/or analyzed in the current study are available from the corresponding author on reasonable request.

\section{Declarations}

\section{Ethics approval and consent to participate}

This study was approved by the Ethics Committee of the First Affiliated Hospital of Sun Yat-sen University and was conducted in accordance with the principles of the Declaration of Helsinki. The need for informed consent to participate and for approval of all patients was waived owing to the retrospective nature of the study and anonymized data.

Consent for publication

Not applicable. 


\section{Competing interests}

The authors declare that they have no competing interests.

Received: 16 November 2020 Accepted: 11 November 2021 Published online: 27 November 2021

\section{References}

1. Bray F, Ferlay J, Soerjomataram I, Siegel RL, Torre LA, Jemal A. Global cancer statistics 2018: GLOBOCAN estimates of incidence and mortality worldwide for 36 cancers in 185 countries. CA Cancer J Clin. 2018:68:394-424.

2. Pan R, Zhu M, Yu C, Lv J, Guo Y, Bian Z, et al. Cancer incidence and mortality: a cohort study in China, 2008-2013. Int J Cancer. 2017;141:1315-23.

3. Information Committee of Korean Gastric Cancer Association. Korean gastric Cancer association Nationwide survey on gastric Cancer in 2014. J Gastric Cancer. 2016;16:131-40.

4. Abdelfatah MM, Barakat M, Lee H, Kim JJ, Uedo N, Grimm I, et al. The incidence of lymph node metastasis in early gastric cancer according to the expanded criteria in comparison with the absolute criteria of the Japanese gastric Cancer association: a systematic review of the literature and meta-analysis. Gastrointest Endosc. 2018;87:338-47.

5. Japanese Gastric Cancer Association. Japanese gastric cancer treatment guidelines 2018 (5th edition). Gastric Cancer. 2020;24:1-21.

6. Kim JP, Kim YW, Yang HK, Noh DY. Significant prognostic factors by multivariate analysis of 3926 gastric cancer patients. World J Surg. 1994;18:872-7.

7. Adachi Y, Mori M, Maehara Y, Sugimachi K. Dukes's classification: a valid prognostic indicator for gastric cancer. Gut. 1994;35:1368-71.

8. Bozzetti F, Bonfanti G, Morabito A, Bufalino R, Menotti V, Andreola $\mathrm{S}$, et al. A multifactorial approach for the prognosis of patients with carcinoma of the stomach after curative resection. Surg Gynecol Obstet. 1986;162:229-34.

9. Liu JY, Deng JY, Zhang NN, Liu HF, Sun WL, He WT, et al. Clinical significance of skip lymph-node metastasis in pN1 gastric-cancer patients after curative surgery. Gastroenterol Rep (Oxf). 2019;7:193-8.

10. Lee SE, Lee JH, Ryu KW, Cho SJ, Lee JY, Kim CG, et al. Sentinel node mapping and skip metastases in patients with early gastric cancer. Ann Surg Oncol. 2009;16:603-8.

11. Kim DH, Choi MG, Noh JH, Sohn TS, Bae JM, Kim S. Clinical significance of skip lymph node metastasis in gastric cancer patients. Eur J Surg Oncol. 2015;41:339-45.

12. Zhao B, Mei D, Zhang J, Luo R, Lu H, Xu H, et al. Impact of skip lymph node metastasis on the prognosis of gastric cancer patients who underwent curative gastrectomy. J BUON. 2019;24:693-700.

13. Choi YY, An JY, Guner A, Kang DR, Cho I, Kwon IG, et al. Skip lymph node metastasis in gastric cancer: is it skipping or skipped? Gastric Cancer. 2016;19:206-15

14. Washington K. 7th edition of the AJCC cancer staging manual: stomach. Ann Surg Oncol. 2010;17:3077-9.

15. Japanese Gastric Cancer Association. Japanese classification of gastric carcinoma - 2nd English edition. Gastric Cancer. 1998;1:10-24.

16. Japanese Gastric Cancer Association. Japanese classification of gastric carcinoma: 3rd English edition. Gastric Cancer. 2011;14:101-12.

17. Amin MB, Greene FL, Edge SB, Compton CC, Gershenwald JE, Brookland RK, et al. The eighth edition AJCC Cancer staging manual: continuing to build a bridge from a population-based to a more "personalized" approach to cancer staging. CA Cancer J Clin. 2017;67:93-9.

18. Choi AH, Nelson RA, Merchant SJ, Kim JY, Chao J, Kim J. Rates of lymph node metastasis and survival in T1a gastric adenocarcinoma in Western populations. Gastrointest Endosc. 2016;83:1184-92.

19. Fukuhara S, Yabe M, Montgomery MM, Itagaki S, Brower ST, Karpeh MS Jr. Race/ethnicity is predictive of lymph node status in patients with early gastric cancer. J Gastrointest Surg. 2014;18:1744-51.

20. Gotoda T, Yanagisawa A, Sasako M, Ono H, Nakanishi Y, Shimoda T, et al. Incidence of lymph node metastasis from early gastric cancer: estimation with a large number of cases at two large centers. Gastric Cancer. 2000;3:219-25.

21. Hirasawa T, Gotoda T, Miyata S, Kato Y, Shimoda T, Taniguchi H, et al. Incidence of lymph node metastasis and the feasibility of endoscopic resection for undifferentiated-type early gastric cancer. Gastric Cancer. 2009; 12:148-52.

22. Abdelfatah MM, Barakat M, Othman MO, Grimm IS, Uedo N. The incidence of lymph node metastasis in submucosal early gastric cancer according to the expanded criteria: a systematic review. Surg Endosc. 2019;33:26-32.

23. Yang HJ, Jang JY, Kim SG, Ahn JY, Nam SY, Kim JH, et al. Risk factors of lymph node metastasis after non-curative endoscopic resection of undifferentiated-type early gastric cancer. Gastric Cancer. 2020;24:168-78.

24. Zong L, Abe M, Seto Y, Ji J. The challenge of screening for early gastric cancer in China. Lancet. 2016;388:2606.

25. Chen W, Zheng R, Baade PD, Zhang S, Zeng H, Bray F, et al. Cancer statistics in China, 2015. CA Cancer J Clin. 2016;66:115-32.

26. Wang $H$, Zhang $H$, Wang $C$, Fang $Y$, Wang $X$, Chen W, et al. Expanded endoscopic therapy criteria should be cautiously used in intramucosal gastric cancer. Chin J Cancer Res. 2016:28:348-54.

27. Ren MH, Qi XS, Chu YN, Yu YN, Chen YQ, Zhang P, et al. Risk of lymph node metastasis and feasibility of endoscopic treatment in ulcerative early gastric cancer. Ann Surg Oncol. 2020;28:2407-17.

28. Su Z, Shu K, Zheng M, Sun X, Fang Z, Wang G. Sentinel lymph node and skip metastases in gastric cancer: a prospective study. Hepatogastroenterology. 2013;60:1513-8.

29. Sowa M, Kato Y, Nishimura M, Kubo T, Maekawa H, Umeyama K. Surgical approach to early gastric cancer with lymph node metastasis. World J Surg. 1989;13:630-5.

30. Huang C, Yu F, Zhao G, Xia X. Postoperative quality of life after laparoscopy-assisted pylorus-preserving gastrectomy compared with laparoscopy-assisted distal gastrectomy for early gastric cancer. J Gastroenterol Hepatol. 2020;35:1712-9.

31. Mao X, Xu X, Zhu H, Ji C, Lu X, Wang B. A comparison between pyloruspreserving and distal gastrectomy in surgical safety and functional benefit with gastric cancer: a systematic review and meta-analysis. World J Surg Oncol. 2020;18:160.

32. Eom BW, Park B, Yoon HM, Ryu KW, Kim YW. Laparoscopy-assisted pylorus-preserving gastrectomy for early gastric cancer: a retrospective study of long-term functional outcomes and quality of life. World J Gastroenterol. 2019;25:5494-504.

33. Nunobe S, Hiki N, Fukunaga T, Tokunaga M, Ohyama S, Seto Y, et al. Laparoscopy-assisted pylorus-preserving gastrectomy: preservation of vagus nerve and infrapyloric blood flow induces less stasis. World J Surg. 2007;31:2335-40

34. Kong SH, Kim JW, Lee HJ, Kim WH, Lee KU, Yang HK. The safety of the dissection of lymph node stations 5 and 6 in pylorus-preserving gastrectomy. Ann Surg Oncol. 2009;16:3252-8.

35. Oh SY, Lee HJ, Yang HK. Pylorus-preserving Gastrectomy for gastric Cancer. J Gastric Cancer. 2016;16:63-71.

36. Barreto SG, Windsor JA. Redefining early gastric cancer. Surg Endosc. 2016;30:24-37.

37. Park DJ, Lee HK, Lee HJ, Lee HS, Kim WH, Yang HK, et al. Lymph node metastasis in early gastric cancer with submucosal invasion: feasibility of minimally invasive surgery. World J Gastroenterol. 2004;10:3549-52.

38. Chen J, Zhao G, Wang Y. Analysis of lymph node metastasis in early gastric cancer: a single institutional experience from China. World J Surg Oncol. 2020;18:57.

39. Zhao B, Huang R, Lu H, Mei D, Bao S, Xu H, et al. Risk of lymph node metastasis and prognostic outcome in early gastric cancer patients with mixed histologic type. Curr Probl Cancer. 2020:100579.

40. Kim SM, Min BH, Ahn JH, Jung SH, An JY, Choi MG, et al. Nomogram to predict lymph node metastasis in patients with early gastric cancer: a useful clinical tool to reduce gastrectomy after endoscopic resection. Endoscopy. 2020;52:435-43.

41. Sugita S, Kinoshita T, Kuwata T, Tokunaga M, Kaito A, Watanabe M, et al. Intramucosal-lymphatic invasion has a slight impact on lymph node metastasis in patients with early gastric cancer. Surg Today. 2020;50(5):484-9

42. Ishigami S, Natsugoe S, Hokita S, Tokushige M, Saihara T, Watanabe T, et al Carcinomatous lymphatic invasion in early gastric cancer invading into the submucosa. Ann Surg Oncol. 1999;6:286-9.

43. Wang Z, Ma L, Zhang XM, Zhou ZX. Risk of lymph node metastases from early gastric cancer in relation to depth of invasion: experience in a single institution. Asian Pac J Cancer Prev. 2014;15:5371-5. 
44. Lin JX, Wang ZK, Wang W, Desiderio J, Xie JW, Wang JB, et al. Risk factors of lymph node metastasis or lymphovascular invasion for early gastric cancer: a practical and effective predictive model based on international multicenter data. BMC Cancer. 2019;19:1048.

45. Zheng Z, Zhang Y, Zhang L, Li Z, Wu X, Liu Y, et al. A nomogram for predicting the likelihood of lymph node metastasis in early gastric patients. BMC Cancer. 2016;16:92.

\section{Publisher's Note}

Springer Nature remains neutral with regard to jurisdictional claims in published maps and institutional affiliations.

- fast, convenient online submission

- thorough peer review by experienced researchers in your field

- rapid publication on acceptance

- support for research data, including large and complex data types

- gold Open Access which fosters wider collaboration and increased citations

- maximum visibility for your research: over 100M website views per year

At BMC, research is always in progress.

Learn more biomedcentral.com/submissions 